\title{
Towards a Better Understanding of the Evolution of Specialized Parasites of Fungus-Growing Ant Crops
}

\author{
Sze Huei Yek, Jacobus J. Boomsma, and Michael Poulsen \\ Centre for Social Evolution, Department of Biology, University of Copenhagen, Universitetsparken 15, \\ 2100 Copenhagen, Denmark
}

Correspondence should be addressed to Sze Huei Yek, syek@bio.ku.dk

Received 5 October 2011; Accepted 12 December 2011

Academic Editor: Alain Lenoir

Copyright () 2012 Sze Huei Yek et al. This is an open access article distributed under the Creative Commons Attribution License, which permits unrestricted use, distribution, and reproduction in any medium, provided the original work is properly cited.

\begin{abstract}
Fungus-growing ants have interacted and partly coevolved with specialised microfungal parasites of the genus Escovopsis since the origin of ant fungiculture about 50 million years ago. Here, we review the recent progress in understanding the patterns of specificity of this ant-parasite association, covering both the colony/population level and comparisons between phylogenetic clades. We use a modified version of Tinbergen's four categories of evolutionary questions to structure our review in complementary approaches addressing both proximate questions of development and mechanism, and ultimate questions of (co)adaptation and evolutionary history. Using the same scheme, we identify future research questions that are likely to be particularly illuminating for understanding the ecology and evolution of Escovopsis parasitism of the cultivar maintained by fungus-growing ants.
\end{abstract}

\section{Introduction}

1.1. The Attine Fungus-Growing Ants. Fungus-growing ants (Hymenoptera: Formicidae: Attini) form a monophyletic tribe of primarily tropical ants that obligately depend on fungal cultivars (Agaricales: mostly Lepiotacea: Leucocoprineae). The ants provide the fungus with optimal growth conditions, and in return, the fungus serves as the main food source for the ants $[1,2]$. The symbiosis between fungus-growing ants and their fungi originated about 50 million years ago [3-6] from a single ancestor that was most likely a generalist forager [3]. Subsequently, the Attini have diversified to encompass approximately 230 described species, distributed across 14 ant genera [4, 7]. Colonies of fungus-growing ants are typically founded by a single queen, who carries a piece of the fungus cultivar from her natal colony in the infrabuccal pocket [8] during her nuptial flight [9-11]. The Attini are divided into the "higher attine" and the phylogenetically basal "lower attine" genera based on their cultivars [5]. Lower attine cultivars are largely unmodified and resemble free-living Leucocoprini, whereas higher attine cultivars (including those of leaf-cutting ants) are highly derived [12].
The clonal propagation of cultivars through vertical transmission $[2,13]$ predicts ancient association and congruence between the ant and fungal cultivar phylogenies. High degrees of congruence have indeed been found at the deep phylogenetic levels in both higher $[14,15]$ and lower attines $[12,14]$. However, the phylogenetic interaction specificity breaks down within, and occasionally between, ant genera and their cultivar strains, indicating that switches and/or reacquisitions of new garden cultivars have occurred (e.g., [12, 16-19]). While the higher-attine fungi no longer persist outside the symbiosis, lower attine fungi have free-living close relatives, which is likely to facilitate gene flow and reacquisitions of symbionts [12]. Cultivar switches can be induced in the laboratory, including the formation of chimeric gardens [20-22]. However, consistent with predictions from host-symbiont conflict theory [23], mature individual colonies appear to consistently maintain a single fungus clone, at least in leaf-cutting ants (Atta and Acromyrmex) where this has been best studied [24, 25].

Clonally propagated monoculture crops are expected to be particularly prone to infection with parasites and pathogens [26], because they represent an attractive resource that should be easy to exploit. This "Red Queen" logic 
$[27,28]$ assumes that parasites and hosts are involved in evolutionary arms races, in which unpredictable genetic heterogeneity, due to sexual recombination, is the most powerful defence against parasites that have short generation times relative to their hosts [28-30]. Single asexual cultivar clones thus seem to represent a liability for the farming symbiosis [25] that needs to be overcome by active protection by the host ants (see below). Colony-level monoculture does not imply population-wide monoculture, as is often the case in modern human crops that are vulnerable to disease. With the possible exception of some species, there is likely to be considerable strain diversity across neighbouring colonies $[16,18]$ that should discourage the spread of infections between colonies.

1.2. Specialised Coevolved Parasites. Microfungal parasites in the genus Escovopsis (anamorphic Hypocreales) have been known for more than a century to overgrow fungus gardens of laboratory colonies $[1,13,31]$, but the formal status of Escovopsis as a disease was confirmed only just over a decade ago when Currie et al. [32] showed that Escovopsis fulfils Koch's four defining postulates [33] for causative disease agents. This included evidence that Escovopsis (i) is found in abundance in diseased but infrequently in apparently healthy colonies, (ii) can be isolated from diseased colonies, (iii) can cause disease when colonies are artificially infected, and (iv) can be reisolated from diseased experimental colonies [32]. It was also shown that Escovopsis has a directly negative impact on the ant cultivar $[32,34,35]$ through the secretion of compounds that break down the cultivar mycelium [36]. As fungus-growing ants rely on healthy fungus gardens for growth and reproduction, this implies that Escovopsis is a potentially serious threat to ant fitness [35].

Deep-level phylogenetic congruence has been found between the fungus-growing ants, their cultivars, and Escovopsis parasites, suggesting a long history of codivergence within the attine agricultural systems [37]. However, cophylogenies at lower levels appear to be punctuated with occasional host switching of the parasites [38], consistent with ongoing arms races [37], although null hypotheses of genetic drift in isolated parasite populations can usually not be dismissed.

Even within ant genera, there is some evidence for antcultivar-Escovopsis pairing specificity. Four morphologically and genetically distinct Escovopsis types parasitize the cultivars maintained by Apterostigma, a basal fungus-growing ant genus [39]. These have so far been categorised as "brown," "yellow," "pink," and "white," but are genetically distinct and likely different subspecies or species (cf. [39]). Even within these groupings, there is evidence for specificity: "pink" Escovopsis appears to infect only G3 cultivars and (rare) "white" Escovopsis only G2 cultivars, whereas "brown" and "yellow" Escovopsis commonly coinfect G2 cultivars (cf. Table 1 in [39]). Current evidence suggests that these pathogen lineages display patterns of phylogenetic congruence with their fungal host [39], maintained by chemotaxis and host resistance in nonnative (i.e., not naturally occurring) combinations [40]. A similar scenario of association specificity is apparent for the lower attine genus Cyphomyrmex, where subclades of a single Escovopsis morphotype (pink) are phylogenetic congruent with corresponding clades of cultivar host genotypes [41]. In the higher attine ants, Trachymyrmex and Sericomyrmex are infected by specific Escovopsis parasites that are phylogenetically distinct from the two clades that parasitize Atta and Acromyrmex leaf-cutting ants $[37,38]$. Within the leaf-cutting ant genera, Escovopsis infections are nonspecific [38], confirming the high degree of ant-cultivar specificity of all extant leaf-cutting ants to a single species of Attamyces symbiont [42].

1.3. Defence Strategies against Escovopsis . Fungus-growing ants, especially the leaf-cutting ants, have elaborate prophylactic fungus grooming and weeding behaviours to keep their cultivar free from parasites [44, 45]. In Acromyrmex, minor workers are particularly efficient at restricting spore germination [45], and major workers appear to recruit minor workers to infected sites, thereby potentially increasing the efficiency of disease suppression [46]. If spores manage to escape the attention of minor workers and germinate, major workers appear to perform the task of removing infected garden pieces (weeding) [45]. Task specialization between castes thus appears to make hygienic policing more efficient in general, which has been proposed to be normally sufficient for eliminating generalist fungal parasites, but not for completely eradicating Escovopsis infections [44].

To control Escovopsis infections, fungus-growing ants may also use metapleural gland secretions, which contain an array of compounds with antibiotic properties $[48,69]$. In a seminal study, Fernández-Marín et al. [47] described highly coordinated and challenge-specific foreleg movements along the metapleural gland opening (metapleural gland grooming), which allowed Atta and Acromyrmex ants to precisely target the application of antibiotic secretion to their gardens. In combination with metapleural gland grooming, fungus-growing ants utilize their infrabuccal pocket (located in the oral cavity) as a further filtering and sterilising device. After grooming, the ants collect Escovopsis spores in this pocket, where they are sterilised by an as-of-yet unknown mechanism (potentially metapleural gland compounds), after which the infrabuccal pellet is expelled on the colony refuse pile $[47,49,70]$.

The cuticle of major garden workers is often covered with a thick white growth of Actinobacteria [50,51], which produce antimicrobial compounds that aid in the protection of the fungal cultivar from Escovopsis [49-51, 64, 71] and possibly other parasites [65]. These beneficial Actinobacteria are reared by the ants and housed in cuticular crypts, tubercles, or other modifications associated with subcuticular exocrine glands [52]. Most work on the Actinobacteria has focused on specifically associated lineages of Pseudonocardia $[51,55]$. Pseudonocardia appears to be vertically transmitted by default [50], but phylogenetic evidence indicates that events of horizontal transfer and incorporation of free-living Pseudonocardia to the symbiosis have occurred [55-57]. Recent studies have further shown that other Actinobacteria 
genera (mainly Streptomyces) are often also present [5761], but their degree of specificity with the symbiosis is less clear. There is little doubt that cuticular Actinobacteria cultures serve active defence functions in the symbiosis, but clarifying the relative importance of predominantly vertically transmitted Pseudonocardia and horizontally transmitted other defensive microbes will need much further work.

Ant cultivars, the hosts of Escovopsis parasitism, are able to launch defences themselves by secreting chemical compounds that suppress Escovopsis growth. This has been tested in the Apterostigma and Cyphomyrmex [41, 43], where antifungal compounds secreted by the cultivar appeared to be more effective in suppressing the growth of Escovopsis strains that are unknown to infect them in nature, but less effective against their native Escovopsis strains [41, 43]. Such cultivar responses towards novel Escovopsis strains might result in limitations for Escovopsis host switching outside the agricultural system that they are adapted to. Overall, therefore, the defences of the ants, the Actinobacteria, and the cultivar appear to reinforce each other in suppressing Escovopsis infection and proliferation within attine ant fungus gardens (see e.g., Figure 10.1 in [22]).

1.4. Trade-Offs between Alternative Defence Functions. Over the course of millions of years of selection on the interaction between fungus-growing ants and Escovopsis, different ant genera have diversified in their specific utilization and combination of alternative defence mechanism to reduce the impact of Escovopsis. This has been best studied in species of the leaf-cutting ant genera Atta and Acromyrmex. Escovopsis infections appear to be more prevalent in Acromyrmex than Atta colonies [35], possibly due to differences in the efficiency of alternative defensive strategies. First, the chemical compounds in the metapleural glands differ between Acromyrmex than Atta, reviewed in [53], making it inevitable that compounds with different antimicrobial properties are produced (cf. [48]). Second, Actinobacteria are abundant in Acromyrmex and essentially absent in Atta [54]. Third, the rate of metapleural gland grooming differs in a contrasting manner, with Atta increasing grooming rates after Escovopsis infection and Acromyrmex maintaining a constantly low rate of metapleural gland grooming [54].

Differences in metapleural gland chemistry, grooming rate, and Actinobacteria coverage indicate that trade-offs between these alternative defensive strategies are likely, conceivably because these defences are known to be costly $[72,73]$. Different defences may target the same parasite, but with different modes of action. For example, in Acromyrmex, metapleural gland secretions kill Escovopsis spores but show limited effect on hyphae [48], while Actinobacteria secretions suppress hyphal growth but do not kill spores [64]. A similar scenario has been proposed for two other genera of higher attine ants, Trachymyrmex and Sericomyrmex, as certain species from the former genus have abundant Actinobacteria cover and low frequencies of metapleural gland grooming, while Sericomyrmex has very few Actinobacteria and a higher frequency of metapleural gland grooming [72].

\section{Using Tinbergen's Four Quadrats to Structure Attine-Escovopsis Research}

Nikolaas Tinbergen was a Dutch ethologist and ornithologist who received a Nobel Prize in Physiology or Medicine in 1973 together with Karl von Frisch and Konrad Lorenz for their joint work on the organization and elicitation of individual and social behaviour in animals [74]. Tinbergen's four categories of evolutionary questions were originally developed to obtain an integrated explanation for animal behaviour, based on complementary understanding of proximate mechanisms (1) and ontogenetic developments (2), as well as ultimate selection forces resulting in adaptive evolution of individuals (3) and long-term evolutionary change of populations or higher-level clades (phylogenetic history) (4) [75]. Tinbergen's framework has since been used in many research programs throughout the life sciences [76-78] but has, to our knowledge, not been applied to host-parasite interactions. For the purpose of the present paper, we modify Tinbergen's framework to encompass a classification of questions that have been (Table 1), or could be (Figure 1), addressed to better understand the evolutionary ecology of attine ant-Escovopsis interactions.

Table 1 summarizes how studies available so far can be grouped into Tinbergen four quadrats framework. This was relatively straightforward for the ultimate questions of adaptive evolution and phylogenetic history, but not always for the proximate ontogeny and mechanism categories, because available research tools have so far not allowed much understanding of the (epi)genetics behind developmental pathways and phenotypic plasticity. It is, therefore, also arguable that the questions addressed in our ontogeny and mechanism categories are rather ambiguous, in being both technologically challenging and relatively imprecise in their fit to a single Tinbergen quadrat. We nonetheless felt that making a first attempt to structure a research agenda was worthwhile and have chosen to group questions of Escovopsis specialization in the ontogeny quadrat and questions of cultivar utilization and defences by the ants and fungal symbionts in the mechanism quadrat. In the sections below, we utilise these groupings to formulate how new experimental work, combined with the increasing availability of genome sequences, may allow novel insights in Escovopsis parasitism.

\section{Tinbergen's Ontogeny Quadrat}

3.1. Escovopsis Recognition of Cultivars. In vitro assays have shown that Escovopsis can recognize native cultivar hosts through chemotaxis, followed by directed growth of the parasite towards the cultivar, the secretion of parasite enzymes breaking down cultivar cells, and absorption of cultivar cell contents [36]. In contrast, Escovopsis is not able to utilize nonnative cultivar strains and can even be inhibited by them $[41,43]$. The mechanisms and genes underlying parasite differentiation between native and nonnative host cultivars remain unknown, that is, we neither know the identity or the evolution of the chemicals (what does Escovopsis recognize?) nor the genes coding for the chemicals produced and their 
TABle 1: Overview of available studies on Escovopsis virulence in gardens of fungus-growing ants, and our assortment of these studies into the four Tinbergen quadrats.

\begin{tabular}{lll}
\hline Quadrat & Study focus & References \\
\hline Ontogeny & Pathology, impact, and prevalence & {$[32,34,35]$} \\
& Genetic and chemical basis of Escovopsis recognition of cultivars & {$[36,38-41,43]$} \\
Mechanism & Ant behavioural defences & {$[44-47]$} \\
& Chemical defences & {$[47,48]$} \\
& Actinobacteria defences & {$[49-52]$} \\
Cultivar defences & {$[40,41,43]$} \\
Phylogeny & Population-level specificity & {$[38-41,43]$} \\
& Cross-phylogeny specificity & {$[38,51]$} \\
Adaptation & Susceptibility/resistance to metapleural gland compounds & $([48]$, reviewed in $[53,54])$ \\
& Degree of Actinobacteria specificity & {$[55-63]$} \\
& Susceptibility/resistance to Actinobacteria secretions & {$[50,58,60,61,64,65]$} \\
\hline
\end{tabular}

\begin{tabular}{|c|c|c|c|}
\hline & \multicolumn{2}{|c|}{ Objects of explanation } \\
\hline & & $\begin{array}{l}\text { Development/Historical } \\
\text { Progression in current form }\end{array}$ & $\begin{array}{l}\text { Single form } \\
\text { What organisms need to function and } \\
\text { why those functions arose }\end{array}$ \\
\hline \multirow{2}{*}{ 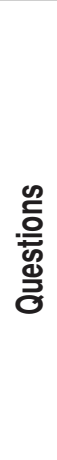 } & $\begin{array}{l}\text { Proximate } \\
\text { How organisms work by describing their } \\
\text { developmental and functional traits }\end{array}$ & $\begin{array}{l}\text { Ontogeny } \\
\text { (i) Escovopsis recognition of cultivars } \\
\text { (ii) Genetic basis for Escovopsis } \\
\text { recognition by the ants } \\
\text { (iii) Trade-offs between alternative } \\
\text { defences }\end{array}$ & $\begin{array}{l}\text { Mechanism } \\
\text { (i) Escovopsis transmission between } \\
\text { colonies } \\
\text { (ii) Colony-level virulence }\end{array}$ \\
\hline & $\begin{array}{l}\text { Evolutionary } \\
\text { How evolution has shaped organisms to } \\
\text { acquire their extant forms }\end{array}$ & $\begin{array}{l}\text { Phylogeny } \\
\text { (i) Origin and diversification of the } \\
\text { association } \\
\text { (ii) Phylo-geographic patterns, } \\
\text { coevolutionary interactions, and } \\
\text { dispersal }\end{array}$ & $\begin{array}{l}\text { Adaptation } \\
\text { (i) Evolutionary potential of } \\
\text { Escovopsis as a parasite } \\
\text { (ii) Evolutionary consequences of } \\
\text { host-parasite interactions }\end{array}$ \\
\hline
\end{tabular}

FIGURE 1: Tinbergen's four quadrat framework applied to evolutionary questions about Escovopsis parasitism of fungus-farming ant crops. Ontogeny refers to the description of development, from DNA to progressive phenotype, mechanism refers to the physiological and cellular processes that organisms have available, phylogeny refers to the idiosyncratic evolutionary history of a lineage, and adaptation refers to traits that acquired their extant function because of specific selective advantages, modified from [66-68].

evolutionary history. Ongoing genome sequencing of cultivars and Escovopsis, as well as efforts to isolate the chemicals involved, will thus allow considerable progress to be made.

Two evolutionary explanations for the maintenance of Escovopsis-cultivar utilization patterns seem possible. The nonadaptive explanation would hold that Escovopsis strains (or species) would be subject to consistent genetic drift in isolated populations, so that they would lose adaptations to allopatric hosts by chance. The alternative adaptive explanation would hold that populations are mostly panmictic, so that genes coding for innovative pathogen traits and defensive recognition and resistance traits of cultivars would tend to coevolve. If so, Escovopsis would track cultivar evolution in continuous, but variable, arms races reminiscent of a geographic mosaic of coevolution [79]. If the latter is the case, expectations are that positive selection on specific gene complexes (e.g., recognition or resistance genes) will likely have left signatures of enhanced $\mathrm{dN} / \mathrm{dS}$ ratios compared to housekeeping and neutral genes, while nonsignificant $\mathrm{dN} / \mathrm{dS}$ ratios would make the nonadaptive null hypothesis more likely. In general, it seems unlikely that Escovopsis populations are highly structured (see also below), but solid empirical evidence on this is lacking.

3.2. Genetic Basis for Escovopsis Recognition by the Ants. Ants are able to discriminate between Escovopsis and other fungi and behave accordingly $[44,45]$. Natural selection in the ant host is expected to select for genes involved in the recognition and removal of Escovopsis from the fungus garden, as this is predicted to provide a selective advantage. Further, Escovopsis has the potential to be much more virulent than any general fungal weeds of attine ant colonies, at least in the higher attine system where virulence has been studied, implying stronger selection on Escovopsis recognition pathways in the 
ants compared to pathways mediating the recognition of weed fungi. The genetic basis of Escovopsis recognition has not been explored, but genomic tools will make this possible in the years to come $[80,81]$. For example, two leaf-cutting ant genomes are now published $[82,83]$ and a sequenced Escovopsis genome will soon follow (anonymous reviewer, personal communication), providing the tools necessary for such new approaches to studying behavioural recognition mechanisms. Recognition of, and concomitant behavioural responses to, Escovopsis infection are faster and last longer than the response to general fungal pathogens [44, 47], leading to the prediction of higher levels of recognition gene expression in the presence of Escovopsis. However, it is conceivable that the mechanism of recognition of Escovopsis and other fungi by the ants does not differ but that responses do, so that it is rather genes underlying behavioural removal responses that are differentially expressed.

3.3. Trade-Offs between Alternative Defences. Defences against Escovopsis include behavioural removal (including self- and allo-grooming), glandular secretions, cultivar defensive compounds against nonnative Escovopsis, and compounds with antibiotic properties derived from Actinobacteria. These defences all involve interactions on the ant cuticle and are expected to require coordinated interactions to avoid negative interference. In Acromyrmex octospinosus, the metapleural gland secretions do not appear to harm the Actinobacteria, so that both defences can be freely expressed [54]. Further, complementarity is expected to maximize costbenefit ratios of defences as well as to avoid redundancies. It is conceivable that differences in Actinobacteria cover between closely related ant species, such as A. octospinosus and A. echinatior [72], reflect more recent adjustments (trade-offs) in the relative importance of defences between the species.

Explorations of defence trade-offs have only been done in some higher attines, leaving questions of this kind unexplored in most of the fourteen extant fungus-growing ant genera. We propose that utilizing the phylogenetic framework of structural modifications over the course of the association between fungus-growing ants and Actinobacteria [52] would offer a good basis for future work to understand the dynamics of defence components across the attine tribe. The relative usage of metapleural gland grooming and the chemistry of glandular and bacterial secretions in Acromyrmex/Trachymyrmex versus Atta/Sericomyrmex exemplify how such comparative approaches can be insightful [54]. However, considering the vast diversity of cultivar usage, Actinobacteria communities, substrate choice, and ant life-history traits, it is conceivable that defence strategies and trade-offs in unstudied attine ants might be different from those found in the higher attines.

\section{Tinbergen's Mechanism Quadrat}

4.1. Escovopsis Transmission between Colonies. The success of parasitism is tightly linked to the transmission frequency between host colonies [84]. The most common transmission for fungal spores is passive dispersal through the air, but this is unlikely to be the case for Escovopsis because it sporulates inside colonies and has wet spores [35]. The mechanism of Escovopsis transmission, therefore, continues to be enigmatic, with untested hypotheses of commensal garden arthropods vectoring spores between colonies, or foraging ants picking up spores via encounters outside the nest as reasonable leads $[41,84]$. Both mechanisms could be further facilitated by attine colonies nesting in each others close proximity. Culture-based attempts to isolate Escovopsis from potential vectors are, therefore, needed for a better understanding of transmission modes. Expectations are that Escovopsis is more likely to be transmitted between colonies by commensal arthropods. This is so, because foragers presumably rarely, if ever, enter other colonies, and are therefore unlikely to pick up Escovopsis spores from nonnative infected colonies, and because workers are efficient at recognizing and removing Escovopsis spores from their cuticle (e.g., $[85,86])$. In contrast, commensal arthropods moving between colonies are not expected to have evolved such avoidance behaviours towards Escovopsis.

4.2. Colony-Level Virulence. The within-nest dynamics of Escovopsis infections remain a frontier awaiting exploration. Escovopsis can coexist with other nonmutualistic filamentous fungi within colonies without colonies displaying signs of infection [62, 87-89]. However, it is not known if infection sets out shortly after Escovopsis introduction, or if Escovopsis spores remain dormant in the colonies until an outbreak of mycelial growth is triggered by external factors. To begin to understand these dynamics, two essential questions need to be addressed. Firstly, we need a better understanding of the level of metabolically active spores and hyphae of Escovopsis in normally functioning and apparently healthy colonies. This could be obtained through quantitative PCR approaches, so that amounts of Escovopsis biomass and levels of metabolic activity, measured as gene expression, can be estimated. Ideally, this should be explored over time to also determine temporal variation. Only when we have a better idea of such dynamics, we can begin to explore the role of the ants in mediating these threats. Secondly, if spore-dormancy is the rule, work should address what factors trigger within-colony outbreaks. One approach that could potentially address this is long-term field surveys of natural colonies to better understand the interplay between ecological fluctuations, (e.g., temperature, rainfall, and food availability), intrinsic factors (e.g., loss of queen, imbalance of worker to garden ratio, and emergence of reproductives), and infection dynamics.

\section{Tinbergen's Phylogeny Quadrat}

5.1. Origin and Diversification of the Association. The apparent presence of Escovopsis throughout the fungus-growing ants suggests that an ancestral Escovopsis was present as a parasite in the first ant cultivars that were domesticated ca. 50 million years ago (cf. $[37,90]$ ). However, an alternative scenario is that Escovopsis parasitism originated shortly after the early attine ants had become irreversibly committed to farming. The latter would indicate that Escovopsis parasitism 
was not merely a passive carry-over process, but that the highly peculiar garden phenotype of domesticated fungi created a novel niche to parasites like Escovopsis. Finding that Escovopsis parasitism would also occur in free-living relatives of lower attine garden symbionts would make an origin predating ant fungiculture more likely, but several lines of indirect evidence suggest that the "new garden niche" model is more likely to apply. First, Actinobacteria cultures on the cuticle of attine ants arose also shortly after these ants became farmers [52], and it would be hard to imagine that the origin of this costly biocontrol habit was not somehow related to Escovopsis infections. Second, the impact of Escovopsis on fungus-growing ant cultivars is likely to be particularly high because colonies keep a high density of cultivar mycelium without sufficient own defences. Third, it is striking that the only clade of attine ants that secondary developed a radically different and much less conspicuous garden phenotype, the yeast-rearing Cyphomyrmex, have secondary lost Escovopsis as a parasite [4].

To date, there are two described species of Escovopsis, with E. weberi from a Brazilian Atta species thought to be the monotypic species of the genus [91]. Later, a morphologically distinct E. aspergilloides was isolated from Trachymyrmex ruthae in Trinidad [92]. Both large scale (cf. [37, 38]) and lower-level lineage diversity [39-41] are considerable, suggesting that there are more Escovopsis species associated with fungus-growing ants. Molecular species delineation based on conserved genes such as EF- $1 \alpha$ and $18 \mathrm{~S}$ rRNA is unlikely to distinguish lineages that diverged recently, so that more sensitive marker studies are needed. Recent multilocus sequence analyses (MLSAs) have provided the opportunity to estimate divergence dates for crucial nodes in phylogenetic trees $[4,19]$ and would thus also offer novel insights when applied to an Escovopsis phylogeny [37]. Approaches of this kind will ultimately allow conclusions about the origin of Escovopsis parasitism (before or after attine ants became farmers) and the rates of Escovopsis evolution in different host clades.

5.2. Phylo-Geographic Patterns, Coevolutionary Interactions, and Dispersal. Coevolutionary theory predicts that genotypic and phenotypic variation across the geographic range of a host-parasite association can lead to parasite adaptations to locally available host genotypes, while becoming maladapted to nonnative genotypes [93]. A prerequisite for such coevolutionary interactions is that host populations are genetically structured, so that gene flow between populations remains limited [93]. In fungus-growing ants, only a single study has attempted to explore such coevolutionary dynamics (in the ant species Apterostigma dentigerum [43]). This showed the presence of six distinct host genotype clusters across Central America, while structuring was essentially absent in the parasite, indicating that Escovopsis genotypes are not tightly tracking those of the host [43].

We would expect that other fungus-growing antcultivar-Escovopsis interactions will mirror the findings in Apterostigma, since cultivars are vertically transmitted by default while Escovopsis is horizontally transmitted. Therefore, the population structure in Escovopsis could be explainable if their sticky spores would use vectors for long distance dispersal that are not available to dispersing ants. It would be tempting to speculate that other arthropods living in attine nests might have this vector function, but examples of such long distance flyers vectoring spores are presently lacking. Alternatively, wind dispersal of small leaf fragments with Escovopsis spores would also seem a realistic mechanism for parasite populations to become less viscous than host populations. Future studies addressing relative dispersal efficiencies of partners in the attine ant symbiosis would seem most informative if they could span geographic areas that would be large enough to include natural barriers that would differentially affect Escovopsis spores and dispersing ant queens transmitting fungus-garden symbionts.

\section{Tinbergen's Adaptation Quadrat}

6.1. Evolutionary Potential of Escovopsis as a Parasite. As already mentioned, Escovopsis has probably persisted as a parasite of fungus-growing ant gardens since the origin of ant fungiculture 50 million years ago $[4,37]$. If that is so, "Red Queen" like arms races with the ant and fungal hosts may have at least periodically occurred, so that genetic diversity of the parasite is likely to be substantial [26-29]. However, the sexual "teleomorph" of Escovopsis has never been observed so that Escovopsis may not have sexual reproduction, similar to many other Ascomycetes [94]. Lack of sex would not necessarily preclude the integration and exchange of genetic material between different anamorphous mycelia within nests, provided that coinfections occur with some frequency. This is because asexual Ascomycetes can undergo genetic exchange between strains after hyphal merging (anastomosis) and parasexual heterokaryosis (the exchange of cell nuclei) [95]. If such exchanges lead to mitotic crossovers, then there is potential for recombination between genetically different strains [95]. It will be very interesting to investigate whether the Escovopsis genome still shows signs of such genetic recombination.

The presence of coinfections within individual nests is a prerequisite for such genetic exchanges. Both Atta and Acromyrmex leaf-cutting ants appear to frequently harbour genetically distinct Escovopsis strains, including ones appearing in two separate phylogenetic clades [63]. Similarly, in the paleoattine genus Apterostigma, fungus gardens are infected by four distinct Escovopsis morphotypes "brown," "yellow," "pink," and "white" [39]. This implies the potential for exchange of genetic material between coinfecting strains within colonies. By explicitly addressing this question, we could gain insight both in the dynamics of coinfections (e.g., facilitation, inhibition, the role of the order of infection precedence) within colonies and in the putative species status of different Escovopsis morphotypes.

6.2. Evolutionary Consequences of Host-Parasite Interactions. A common question in the evolutionary study of host-pathogen interactions is whether coevolutionary arms races are almost continuous or relatively rare. This is partly because of the difficulty of testing such dynamics when exploring 
biological systems in real time. Fungus-growing ants have evolved extensive complementary defences to deal with Escovopsis, but the parasite nevertheless prevails at relatively high population-level frequencies, ranging from $27-75 \%$, depending on the ant genus and geographic location (e.g., [32, 88]). This finding suggests that Escovopsis continues to exert selection pressure on the ant hosts, potentially leading to concomitant changes in ant defences. All this is suggestive of, but not decisive evidence for, antagonistic coevolution (cf. [96]).

The efficiency of behavioural defences (grooming/weeding) in attine ants is known to have an impact on the virulence of Escovopsis [44, 45]. Under a coevolutionary scenario, expectations are that Escovopsis has exerted selection pressures on the ants to optimize their behavioural response towards native parasite strains. Such a scenario would predict that infections with (avirulent) nonnative strains of the parasite would not elicit the same efficient response from the ants. Similarly, if metapleural gland grooming behaviour and chemistry have been shaped by coevolutionary interactions with Escovopsis, then we would expect that the grooming rate and the chemical secretion cocktail would be adapted to inhibit native parasite strains more than nonnative strains.

The coevolutionary patterns arising from interactions between Escovopsis and the Actinobacteria are inevitably different from those between Escovopsis and direct defences by the ants. Two, perhaps nonmutually exclusive, scenarios derived from Red-Queen dynamics in relation to Actinobacteria defence have been proposed. The first scenario suggests that Actinobacteria in the genus Pseudonocardia evolve in response to antibiotic resistance evolving in Escovopsis. Evidence supporting the potential for this to be the case comes mainly from observations of variation in the propensities of different Pseudonocardia-derived antibiotics, including the presence of Escovopsis strains that are resistant $[55,64]$. Phenotypic variation is a prerequisite for such dynamics to be maintained, as this is what natural selection can act on. However, no studies have as yet shown that changes in Pseudonocardia genes for antibiotic production do indeed change in response to Escovopsis susceptibility. A second possible scenario is that attine ants frequently acquire strains of bacteria from the environment that have novel antibiotic properties against Escovopsis, be it either Pseudonocardia [55] or other Actinobacteria [57, 61, 65]. Evidence for such acquisitions comes from survey data showing that free-living Pseudonocardia are phylogenetically interspersed with ant-associated clades [55], and that additional Actinobacteria with antibiotic properties (mainly Streptomyces) can be obtained from the ant cuticles or gardens of colonies. We expect that characterizations of the antibiotic profiles produced by the major clades of Pseudonocardia that associate with fungus-growing ants will clarify the role that these alternative acquisition mechanisms have played in maintaining a successful Pseudonocardia-defence against Escovopsis. Further studies will also benefit from a more explicit emphasis on exploring how and to what extent such horizontal acquisitions of novel Actinobacteria occur, and whether they have a selective advantage for ant colony fitness.

\section{Conclusions}

Since the discovery of Escovopsis parasitism of fungusgrowing ants less than 15 years ago, we have obtained a broad understanding of prevalence, impact, role, and coevolution of the parasite with the attine ant-fungus symbiosis. Nevertheless, many fundamental questions remain unanswered, including the origin of the host-parasite association, its presence and potential role outside attine ant nests, parasite transmission between colonies, and within-colony disease dynamics. We know that Escovopsis is attracted to specific ant cultivars in some cases, but the generality of this phenomenon and the underlying recognition mechanisms are unknown. Several defences against Escovopsis are known, including prophylactic behaviours, metapleural gland grooming and compounds, and Actinobacteria symbionts, which all contribute to reducing the impact of Escovopsis. However, we know little about the context-specific efficiency of these alternative and complementary defences, and only in some cases do we have a crude understanding of the potential trade-offs involved. More detailed phylogenetic studies of the association specificity of ants, fungal cultivars, Escovopsis, and Actinobacteria are needed to improve our interpretations of reciprocal interactions observed. Although the Tinbergen framework did not allow us to do full justice to the complexity of this host-parasite interaction, we feel that it does provide a useful structuring device for the research agenda that will be required to make further progress in understanding this unique genus of crop-pests of fungusgrowing ants.

\section{Acknowledgments}

The authors thank Panagiotis Sapountzis, Jelle van Zweden, Eric Caldera, and Jeremy Thomas Poulsen for comments on an early draft of this manuscript, and three anonymous reviewers for valuable comments and suggestions. S. H. Yek and J. J. Boomsma were supported by the Danish National Research Foundation, and M. Poulsen by The Danish Council for Independent Research, Natural Sciences (FNU).

\section{References}

[1] F. W. Møller, Die Pilzgärten Einiger Südamerikanischer Ameisen, Gustav Fischer, Jena, Germany, 1893.

[2] N. A. Weber, Gardening Ants: The Attines, American Philosophical Society, Philadelphia, Pa, USA, 1972.

[3] U. G. Mueller, T. R. Schultz, C. R. Currie, R. M. M. Adams, and D. Malloch, "The origin of the attine ant-fungus mutualism," The Quarterly Review of Biology, vol. 76, no. 2, pp. 169-197, 2001.

[4] T. R. Schultz and S. G. Brady, "Major evolutionary transitions in ant agriculture," Proceedings of the National Academy of Sciences of the United States of America, vol. 105, no. 14, pp. 54355440, 2008.

[5] T. R. Schultz and R. Meier, "A phylogenetic analysis of the fungus-growing ants (Hymenoptera: Formicidae: Attini) based on morphological characters of the larvae," Systematic Entomology, vol. 20, no. 4, pp. 337-370, 1995. 
[6] J. K. Wetterer, T. R. Schultz, and R. Meier, "Phylogeny of fungus-growing ants (tribe attini) based on mtDNA sequence and morphology," Molecular Phylogenetics and Evolution, vol. 9, no. 1, pp. 42-47, 1998.

[7] C. Klingenberg and C. R. F. Brandão, "Revision of the fungusgrowing ant genera Mycetophylax Emery and Paramycetophylax Kusnezov rev. stat., and description of Kalathomyrmex n. gen. (Formicidae: Myrmicinae: Attini)," Zootaxa, no. 2052, pp. $1-31,2009$.

[8] T. Eisner and G. M. Happ, "The infrabuccal pocket of a formicine ant: a social filtration device," Psyche, vol. 69, pp. 107-116, 1962.

[9] B. Hölldobler and E. O. Wilson, The Ants, Springer Verlag, Berlin, Germany, 1990.

[10] H. von Ihering, "Die anlage neuer colonien und pilzgärten bei," Atta Sexdens. Zoologischer Anzeiger, vol. 21, pp. 238-245, 1898.

[11] M. Autuori, "La fondation des sociétés chez le fourmis champignnonnistes du genre "Atta" (Hym. Formicidae)," in L'Instinct dans le Comportement des Animaux et de L'Homme, M. Autuori et al., Ed., Masson \& Cie, Paris, France, 1956.

[12] U. G. Mueller, S. A. Rehner, and T. R. Schultz, "The evolution of agriculture in ants," Science, vol. 281, no. 5385, pp. 20342038, 1998.

[13] N. A. Weber, "Fungus-growing ants," Science, vol. 153, no. 3736, pp. 587-604, 1966.

[14] I. H. Chapela, S. A. Rehner, T. R. Schultz, and U. G. Mueller, "Evolutionary history of the symbiosis between fungusgrowing ants and their fungi," Science, vol. 266, no. 5191, pp. 1691-1694, 1994.

[15] G. Hinkle, J. K. Wetterer, T. R. Schultz, and M. L. Sogin, "Phylogeny of the attine ant fungi based on analysis of small subunit ribosomal RNA gene sequences," Science, vol. 266, no. 5191, pp. 1695-1697, 1994.

[16] A. S. Mikheyev, U. G. Mueller, and J. J. Boomsma, "Population genetic signatures of diffuse co-evolution between leaf-cutting ants and their cultivar fungi," Molecular Ecology, vol. 16, no. 1, pp. 209-216, 2007.

[17] A. S. Mikheyev, T. Vo, and U. G. Mueller, "Phylogeography of post-pleistocene population expansion in a fungus-gardening ant and its microbial mutualists," Molecular Ecology, vol. 17, no. 20, pp. 4480-4488, 2008.

[18] A. M. Green, U. G. Mueller, and R. M. M. Adams, "Extensive exchange of fungal cultivars between sympatric species of fungus-growing ants," Molecular Ecology, vol. 11, no. 2, pp. 191-195, 2002.

[19] A. S. Mikheyev, U. G. Mueller, and P. Abbot, "Comparative dating of attine ant and lepiotaceous cultivar phylogenies reveals coevolutionary synchrony and discord," The American Naturalist, vol. 175, no. 6, pp. E126-E133, 2010.

[20] R. Sen, H. D. Ishak, T. R. Kniffin, and U. G. Mueller, "Construction of chimaeric gardens through fungal intercropping: a symbiont choice experiment in the leafcutter ant Atta texana (Attini, Formicidae)," Behavioral Ecology and Sociobiology, vol. 64, no. 7, pp. 1125-1133, 2010.

[21] R. M. M. Adams, U. G. Mueller, A. K. Holloway, A. M. Green, and J. Narozniak, "Garden sharing and garden stealing in fungus-growing ants," Naturwissenschaften, vol. 87, no. 11, pp. 491-493, 2000.

[22] M. Poulsen, A. E. F. Little, and C. R. Currie, "Fungus-growing ant-microbe symbioses: using microbes to defend beneficial mutualisms within symbiotic communities," in Defensive
Mutualism in Microbial Symbiosis, J. F. White and M. S. Torres, Eds., CRC Press, Boca Raton, Fla, USA, 2009.

[23] S. A. Frank, "Models of parasite virulence," The Quarterly Review of Biology, vol. 71, no. 1, pp. 37-78, 1996.

[24] M. Poulsen and J. J. Boomsma, "Mutualistic fungi control crop diversity in fungus-growing ants," Science, vol. 307, no. 5710, pp. 741-744, 2005.

[25] U. G. Mueller, J. J. Scott, H. D. Ishak, M. Cooper, and A. Rodrigues, "Monoculture of leafcutter ant gardens," PLoS One, vol. 5, no. 9, Article ID e12668, 2010.

[26] K. Clay and P. X. Kover, "The Red Queen Hypothesis and plant/pathogen interactions," Annual Review of Phytopathology, vol. 34, pp. 29-50, 1996.

[27] W. D. Hamilton, "Sex versus non-sex versus parasite," Oikos, vol. 35, no. 2, pp. 282-290, 1980.

[28] L. T. Morran, O. G. Schmidt, I. A. Gelarden, R. C. Parrish II, and C. M. Lively, "Running with the Red Queen: host-parasite coevolution selects for biparental sex," Science, vol. 333, no. 6039, pp. 216-218, 2011.

[29] R. J. Ladle, "Parasites and sex: catching the red queen," Trends in Ecology and Evolution, vol. 7, no. 12, pp. 405-408, 1992.

[30] J. Jokela, M. F. Dybdahl, and C. M. Lively, "The maintenance of sex, clonal dynamics, and host-parasite coevolution in a mixed population of sexual and asexual snails," The American Naturalist, vol. 174, no. 1, pp. S43-S53, 2009.

[31] G. Stahel and D. C. Geijskes, "Weitere untersuchungen über nestbau und gartenpilz von Atta cephalotes L. und Atta sexdens L. (Hym. Formicidae)," Revista Entomology, vol. 12, pp. 243268, 1940.

[32] C. R. Currie, U. G. Mueller, and D. Malloch, "The agricultural pathology of ant fungus gardens," Proceedings of the National Academy of Sciences of the United States of America, vol. 96, no. 14, pp. 7998-8002, 1999.

[33] R. Koch, "Üeber den augenblicklichen stand der bakteriologischen choleradiagnose," Zeitschrift für Hygiene und Infektionskrankheiten, vol. 14, no. 1, pp. 319-338, 1893.

[34] C. R. Currie, The ecology and evolution of a quadripartite symbiosis: examining the interactions among attine ants, fungi, and actinomycetes, Ph.D. thesis, Department of Botany, University of Toronto, 2000.

[35] C. R. Currie, "Prevalence and impact of a virulent parasite on a tripartite mutualism," Oecologia, vol. 128, no. 1, pp. 99-106, 2001.

[36] H. T. Reynolds and C. R. Currie, "Pathogenicity of Escovopsis weberi: the parasite of the attine ant-microbe symbiosis directly consumes the ant-cultivated fungus," Mycologia, vol. 96, no. 5, pp. 955-959, 2004.

[37] C. R. Currie, B. Wong, A. E. Stuart et al., "Ancient tripartite coevolution in the attine ant-microbe symbiosis," Science, vol. 299, no. 5605, pp. 386-388, 2003.

[38] S. J. Taerum, M. J. Cafaro, A. E. F. Little, T. R. Schultz, and C. R. Currie, "Low host-pathogen specificity in the leaf-cutting ant-microbe symbiosis," Proceedings of the Royal Society B, vol. 274, no. 1621, pp. 1971-1978, 2007.

[39] N. M. Gerardo, U. G. Mueller, and C. R. Currie, "Complex host-pathogen coevolution in the Apterostigma fungus-growing ant-microbe symbiosis," BMC Evolutionary Biology, vol. 6, article 88, 2006.

[40] N. M. Gerardo, S. R. Jacobs, C. R. Currie, and U. G. Mueller, "Ancient host-pathogen associations maintained by specificity of chemotaxis and antibiosis," PLoS Biology, vol. 4, no. 8, pp. 1358-1363, 2006. 
[41] N. M. Gerardo, U. G. Mueller, S. L. Price, and C. R. Currie, "Exploiting a mutualism: parasite specialization on cultivars within the fungus-growing ant symbiosis," Proceedings of the Royal Society B, vol. 271, no. 1550, pp. 1791-1798, 2004.

[42] A. S. Mikheyev, U. G. Mueller, and P. Abbot, "Cryptic sex and many-to-one coevolution in the fungus-growing ant symbiosis," Proceedings of the National Academy of Sciences of the United States of America, vol. 103, no. 28, pp. 10702-10706, 2006.

[43] N. M. Gerardo and E. J. Caldera, "Labile associations between fungus-growing ant cultivars and their garden pathogens," The ISME Journal, vol. 1, no. 5, pp. 373-384, 2007.

[44] C. R. Currie and A. E. Stuart, "Weeding and grooming of pathogens in agriculture by ants," Proceedings of the Royal Society B, vol. 268, no. 1471, pp. 1033-1039, 2001.

[45] D. Abramowski, C. R. Currie, and M. Poulsen, "Caste specialization in behavioral defenses against fungus garden parasites in Acromyrmex octospinosus leaf-cutting ants," Insectes Sociaux, vol. 58, no. 1, pp. 65-75, 2010.

[46] A. Gerstner, M. Poulsen, and C. R. Currie, "Recruitment of minor workers for defense against a specialized parasite of Atta leaf-cutting ant fungus gardens," Ethology, Ecology and Evolution, vol. 23, no. 1, pp. 61-75, 2011.

[47] H. Fernández-Marín, J. K. Zimmerman, S. A. Rehner, and W. T. Wcislo, "Active use of the metapleural glands by ants in controlling fungal infection," Proceedings of the Royal Society $B$, vol. 273, no. 1594, pp. 1689-1695, 2006.

[48] A. N. M. Bot, D. Ortius-Lechner, K. Finster, R. Maile, and J. J. Boomsma, "Variable sensitivity of fungi and bacteria to compounds produced by the metapleural glands of leaf-cutting ants," Insectes Sociaux, vol. 49, no. 4, pp. 363-370, 2002.

[49] A. E. F. Little, T. Murakami, U. G. Mueller, and C. R. Currie, "Defending against parasites: fungus-growing ants combine specialized behaviours and microbial symbionts to protect their fungus gardens," Biology Letters, vol. 2, no. 1, pp. 12-16, 2006.

[50] C. R. Currie, J. A. Scott, R. C. Summerbell, and D. Malloch, "Erratum: fungus-growing ants use antibiotic-producing bacteria to control garden parasites," Nature, vol. 398, pp. 701704, 1999.

[51] C. R. Currie, A. N. M. Bot, and J. J. Boomsma, "Experimental evidence of a tripartite mutualism: bacteria protect ant fungus gardens from specialized parasites," Oikos, vol. 101, no. 1, pp. 91-102, 2003.

[52] C. R. Currie, M. Poulsen, J. Mendenhall, J. J. Boomsma, and J. Billen, "Coevolved crypts and exocrine glands support mutualistic bacteria in fungus-growing ants," Science, vol. 311, no. 5757, pp. 81-83, 2006.

[53] S. H. Yek and U. G. Mueller, "The metapleural gland of ants," Biological Reviews, vol. 91, no. 3-4, pp. 201-224, 2010.

[54] H. Fernández-Marín, J. K. Zimmerman, D. R. Nash, J. J. Boomsma, and W. T. Wcislo, "Reduced biological control and enhanced chemical pest management in the evolution of fungus farming in ants," Proceedings of the Royal Society B, vol. 276, no. 1665, pp. 2263-2269, 2009.

[55] M. J. Cafaro, M. Poulsen, A. E. F. Little et al., "Specificity in the symbiotic association between fungus-growing ants and protective Pseudonocardia bacteria," Proceedings of the Royal Society B, vol. 278, no. 1713, pp. 1814-1822, 2011.

[56] M. Poulsen, M. Cafaro, J. J. Boomsma, and C. R. Currie, "Specificity of the mutualistic association between actinomycete bacteria and two sympatric species of Acromyrmex leaf-cutting ants," Molecular Ecology, vol. 14, no. 11, pp. 3597-3604, 2005.
[57] U. G. Mueller, D. Dash, C. Rabeling, and A. Rodrigues, "Coevolution between attine ants and actinomycete bacteria: a reevaluation," Evolution, vol. 62, no. 11, pp. 2894-2912, 2008.

[58] S. Haeder, R. Wirth, H. Herz, and D. Spiteller, "Candicidinproducing Streptomyces support leaf-cutting ants to protect their fungus garden against the pathogenic fungus Escovopsis," Proceedings of the National Academy of Sciences of the United States of America, vol. 106, no. 12, pp. 4742-4746, 2009.

[59] C. Kost, T. Lakatos, I. Bottcher, W. R. Arendholz, M. Redenbach, and R. Wirth, "Non-specific association between filamentous bacteria and fungus-growing ants," Naturwissenschaften, vol. 94, no. 10, pp. 821-828, 2007.

[60] J. Barke, R. F. Seipke, S. Grüschow et al., "A mixed community of actinomycetes produce multiple antibiotics for the fungus farming ant Acromyrmex octospinosus," BMC Biology, vol. 8, no. 1 , article 109, 2010.

[61] I. Schoenian, M. Spiteller, M. Ghaste, R. Wirth, H. Herz, and D. Spiteller, "Chemical basis of the synergism and antagonism in microbial communities in the nests of leaf-cutting ants," Proceedings of the National Academy of Sciences of the United States of America, vol. 108, no. 5, pp. 1955-1960, 2011.

[62] A. Rodrigues, F. C. Pagnocca, M. Bacci Jr., M. J. A. Hebling, O. C. Bueno, and L. H. Pfenning, "Variability of non-mutualistic filamentous fungi associated with Atta sexdens rubropilosa nests," Folia Microbiologica, vol. 50, no. 5, pp. 421-425, 2005.

[63] S. J. Taerum, M. Cafaro, and C. R. Currie, "Presence of multiparasite infections within individual colonies of leaf-cutter ants," Environmental Entomology, vol. 39, no. 1, pp. 105-113, 2010.

[64] M. Poulsen, D. Erhardt, A. E. F. Little et al., "Variation in Pseudonocardia antibiotic defence helps govern parasite-induced morbidity in Acromyrmex leaf-cutting ants," Environmental Microbiology Reports, vol. 2, no. 4, pp. 534-540, 2010.

[65] R. Sen, H. D. Ishak, E. Dora, S. E. Dowd, E. Hong, and U. G. Mueller, "Generalized antifungal activity and 454-screening of Pseudonocardia and Amycolatopsis bacteria in nests of fungusgrowing ants," Proceedings of the National Academy of Sciences of the United States of America, vol. 106, no. 42, pp. 1780517810, 2009.

[66] R. M. Nesse, “Tinbergen's Four Questions Organized,” 2000, http://nesse.us.

[67] N. Tinbergen, "On aims and methods of ethology," Zeitschrift für Tierpsychologie, vol. 20, no. 4, pp. 410-433, 1963.

[68] E. Mayr, "Adaptation and selection," Italian Journal of Zoology, vol. 48, pp. 66-77, 1981.

[69] D. Ortius-Lechner, R. Maile, E. D. Morgan, and J. J. Boomsma, "Metapleural gland secretion of the leaf-cutter ant Acromyrmex octospinosus: new compounds and their functional significance," Journal of Chemical Ecology, vol. 26, no. 7, pp. 1667-1683, 2000.

[70] A. E. F. Little, T. Murakami, U. G. Mueller, and C. R. Currie, "The infrabuccal pellet piles of fungus-growing ants," Ethology, Ecology and Evolution, vol. 90, no. 12, pp. 558-562, 2003.

[71] D. C. Oh, M. Poulsen, C. R. Currie, and J. Clardy, "Dentigerumycin: a bacterial mediator of an ant-fungus symbiosis," Nature Chemical Biology, vol. 5, no. 6, pp. 391-393, 2009.

[72] M. Poulsen, A. N. M. Bot, M. G. Nielsen, and J. J. Boomsma, "Experimental evidence for the costs and hygienic significance of the antibiotic metapleural gland secretion in leaf-cutting ants," Behavioral Ecology and Sociobiology, vol. 52, no. 2, pp. 151-157, 2002.

[73] M. Poulsen, A. N. M. Bot, C. R. Currie, M. G. Nielsen, and J. J. Boomsma, "Within-colony transmission and the cost of a mutualistic bacterium in the leaf-cutting ant Acromyrmex 
octospinosus," Functional Ecology, vol. 17, no. 2, pp. 260-269, 2003.

[74] D. A. Dewsbury, “The 1973 Nobel prize for physiology or medicine: recognition for behavioral science?” American Psychologist, vol. 58, no. 9, pp. 747-752, 2003.

[75] J. R. Krebs and N. B. Davies, An Introduction to Behavioural Ecology, Blackwell Publisher, 1993.

[76] E. L. Charnov and S. W. Skinner, "Complementary approaches to the understanding of parasitoid oviposition decisions," Environmental Entomology, vol. 14, no. 4, pp. 383-391, 1985.

[77] D. M. Zeifman, "An ethological analysis of human infant crying: answering Tinbergen's four questions," Developmental Psychobiology, vol. 39, no. 4, pp. 265-285, 2001.

[78] R. Buchholz, "Behavioural biology: an effective and relevant conservation tool," Trends in Ecology and Evolution, vol. 22, no. 8, pp. 401-407, 2007.

[79] J. N. Thompson, "Specific hypotheses on the geographic mosaic of coevolution," The American Naturalist, vol. 153, no. S5, pp. S1-S14, 1999.

[80] M. E. Hudson, "Sequencing breakthroughs for genomic ecology and evolutionary biology," Molecular Ecology Resources, vol. 8, no. 1, pp. 3-17, 2008.

[81] A. Rokas and P. Abbot, "Harnessing genomics for evolutionary insights," Trends in Ecology and Evolution, vol. 24, no. 4, pp. 192-200, 2009.

[82] S. Nygaard, G. J. Zhang, M. Schiøtt et al., "The genome of the leaf-cutting ant Acromyrmex echinatior suggests key adaptations to advanced social life and fungus farming," Genome Research, vol. 21, pp. 1339-1348, 2011.

[83] G. Suen, C. Teiling, L. Li et al., "The genome sequence of the leaf-cutter ant Atta cephalotes reveals insights into its obligate symbiotic lifestyle," PLoS Genetics, vol. 7, no. 2, Article ID e1002007, 2011.

[84] R. M. Anderseon and R. M. May, "The population dynamics of microparasites and their invertebrate hosts," Philosophical Transactions of the Royal Society of London B, vol. 291, no. 1054, pp. 451-524, 1981.

[85] C. R. Currie, "A community of ants, fungi, and bacteria: a multilateral approach to studying symbiosis," Annual Review of Microbiology, vol. 55, pp. 357-380, 2001.

[86] H. Fernández-Marín, J. K. Zimmerman, and W. T. Wcislo, "Nest-founding in Acromyrmex octospinosus (Hymenoptera, Formicidae, Attini): demography and putative prophylactic behaviors," Insectes Sociaux, vol. 50, no. 4, pp. 304-308, 2003.

[87] F. J. Richard and C. Errard, "Hygienic behavior, liquidforaging, and trophallaxis in the leafcutting ants, Acromyrmex subterraneus and Acromyrmex octospinosus," Journal of Insect Science, vol. 9, article 63, 2009.

[88] A. Rodrigues, M. Bacci Jr., U. G. Mueller, A. Ortiz, and F. C. Pagnocca, "Microfungal "weeds" in the leafcutter ant symbiosis," Microbial Ecology, vol. 56, no. 4, pp. 604-614, 2008.

[89] A. Rodrigues, U. G. Mueller, H. D. Ishak, M. Bacci Jr., and F. C. Pagnocca, "Ecology of microfungal communities in gardens of fungus-growing ants (Hymenoptera: Formicidae): a year-long survey of three species of attine ants in Central Texas," FEMS Microbiology Ecology, vol. 78, no. 2, pp. 244-255, 2011.

[90] E. Caldera, M. Poulsen, G. Suen, and C. R. Currie, "Insect symbioses - a case study of past, present, and future fungusgrowing ant research," Environmental Entomology, vol. 38, no. 1, pp. 78-92, 2009.

[91] J. J. Muchovej and T. M. Della Lucia, "Escovopsis, a new genus from leaf cutting ant nests to replace Phialocladus nomem invalidum," Mycotaxon, vol. 37, pp. 191-195, 1990.
[92] K. A. Seifert, R. A. Samson, and I. H. Chapela, "Escovopsis aspergilloides, a rediscovered Hyphomycete from leaf-cutting ant nests," Mycologia, vol. 87, no. 3, pp. 407-413, 1995.

[93] J. N. Thompson, The Geographic Mosaic of Coevolution, The University of Chicago Press, Chicago, Ill, USA, 2005.

[94] D. H. Jennings and G. Lysek, Fungal Biology: Understanding the Fungal Lifestyle, Bios Scientific Publishers, Guildford, UK, 1996.

[95] R. D. Tinline and B. H. MacNeill, "Parasexuality in plant pathogenic fungi," Annual Review of Phytopathology, vol. 7, pp. 147-168, 1969.

[96] A. Buckling and P. B. Rainey, "Antagonistic coevolution between a bacterium and a bacteriophage," Proceedings of the Royal Society B, vol. 269, no. 1494, pp. 931-936, 2002. 

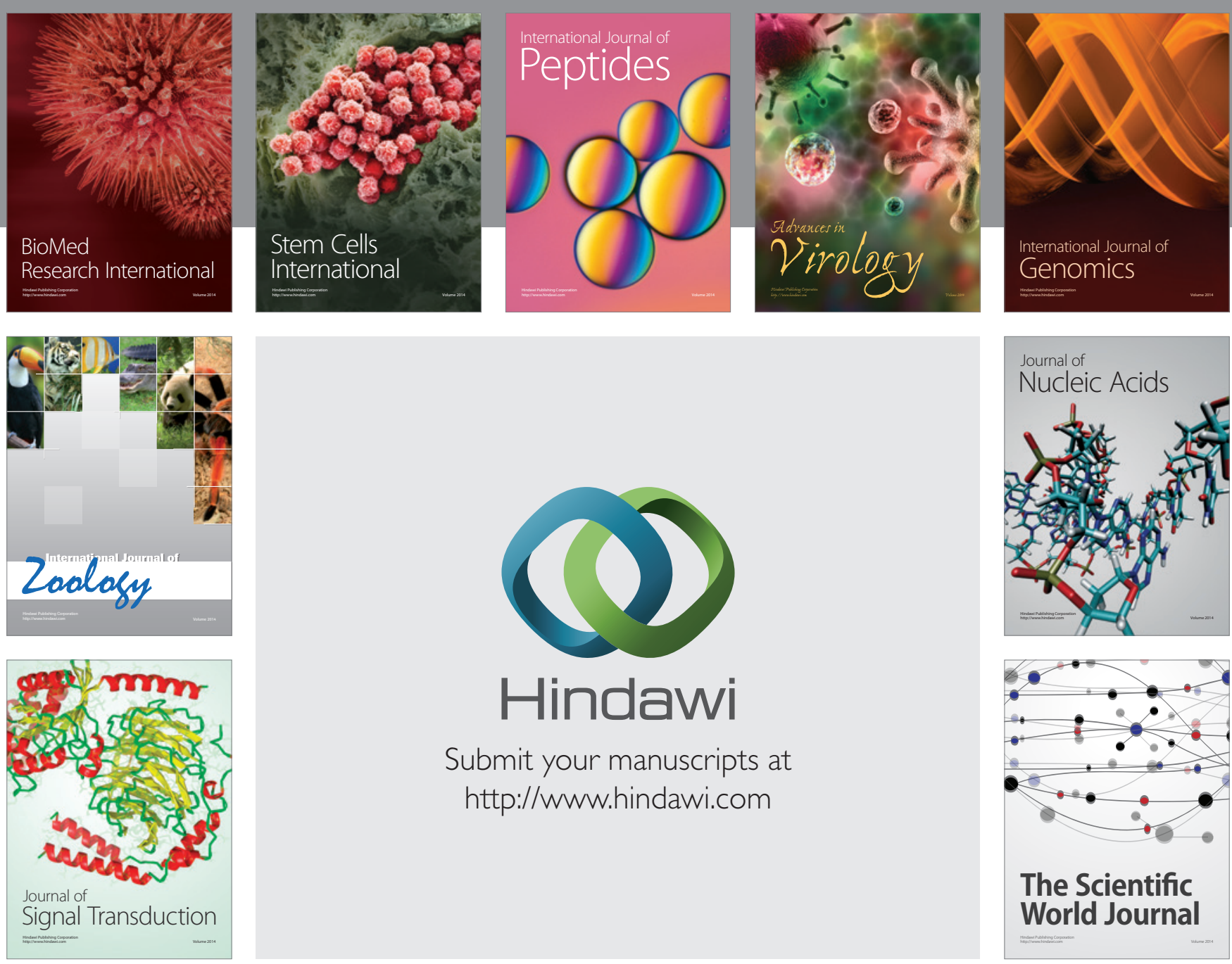

Submit your manuscripts at

http://www.hindawi.com
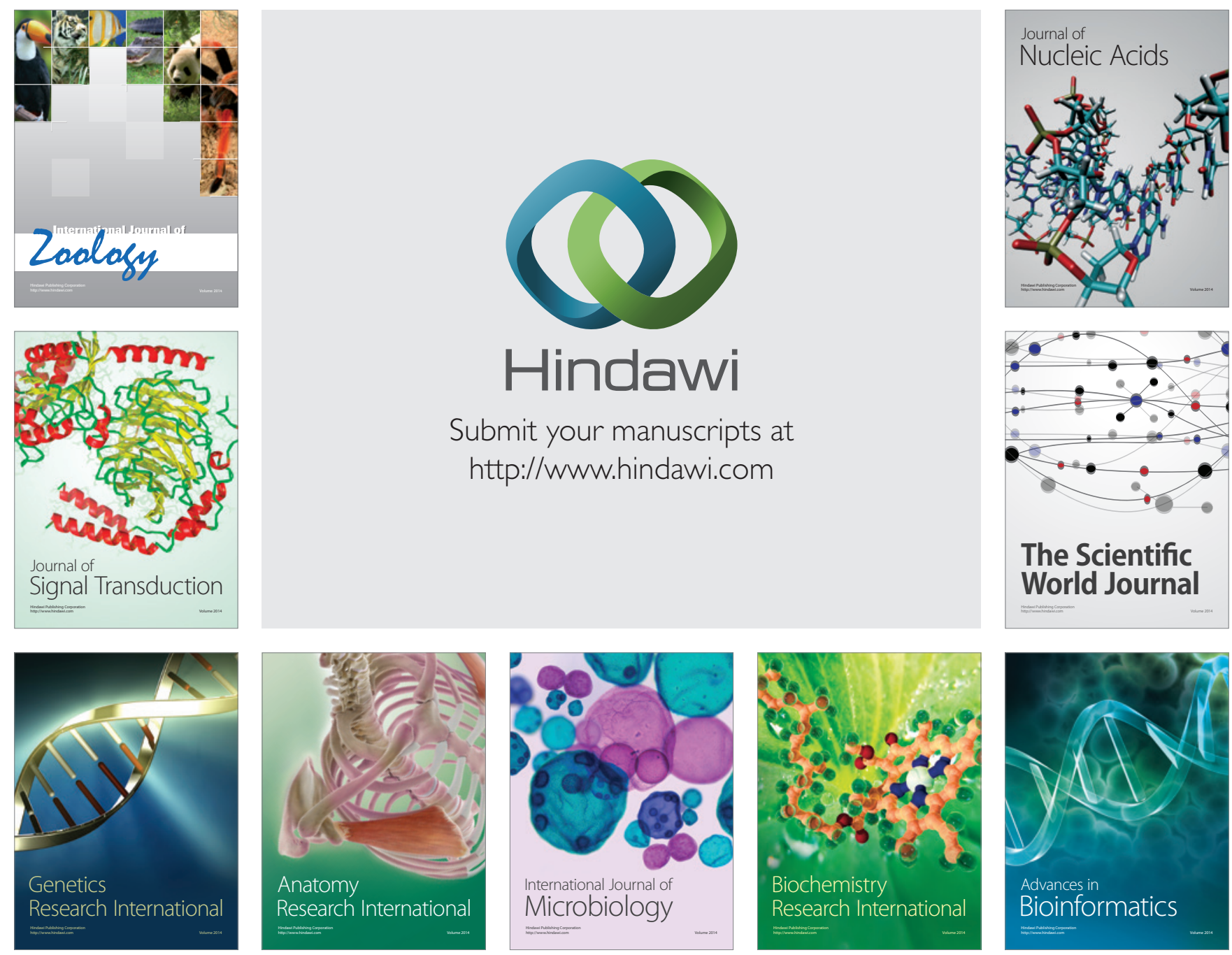

The Scientific World Journal
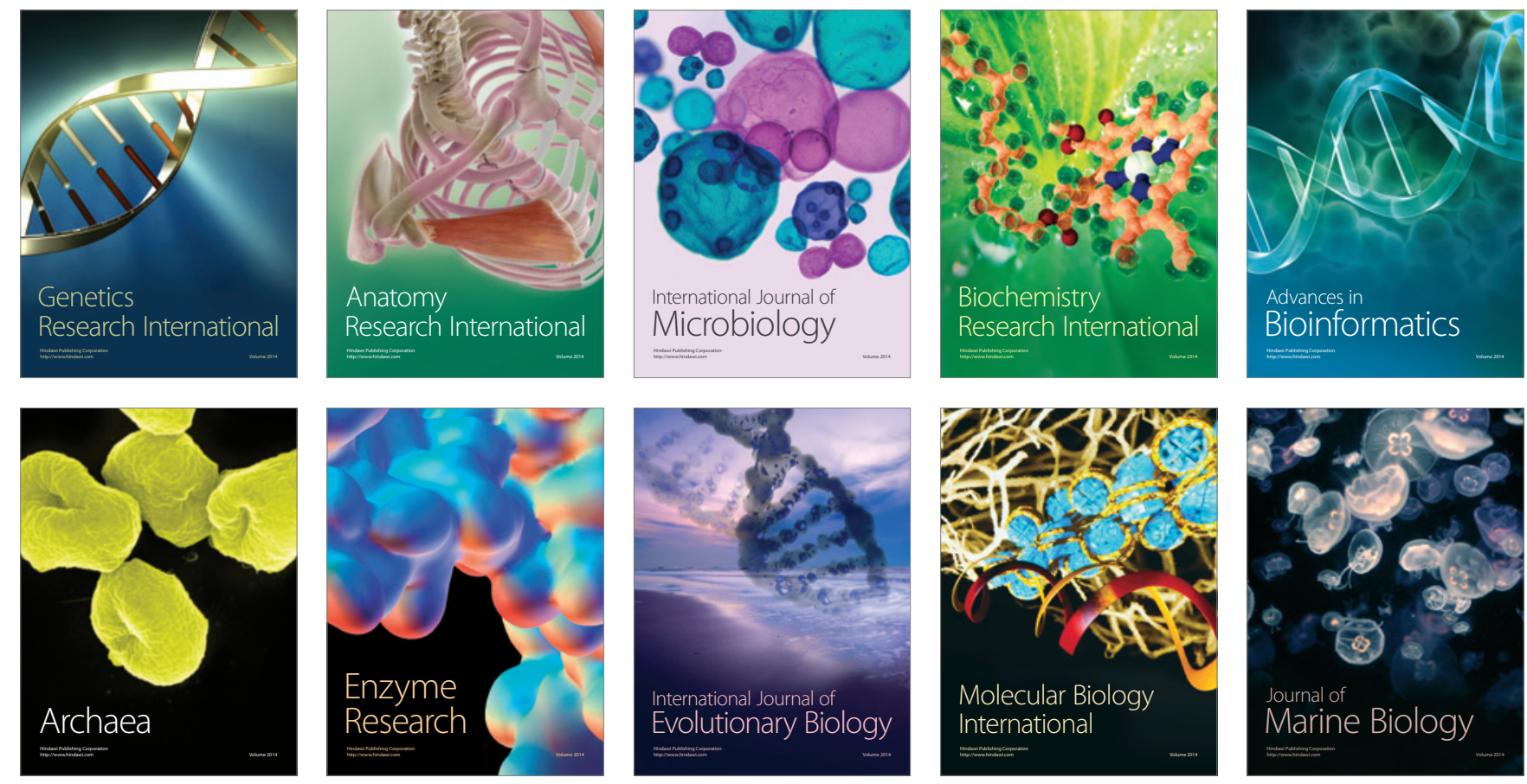